\title{
SOB O SIGNO DA FRAUDE: UMA PERSONAGEM AUTO-ILUDIDA
}

\author{
Edimilson Dezan*
}

$\mathbf{E}$

ste estudo procura examinar a retórica discursiva que permeia o conto A igreja do Diabo, de Machado de Assis (1983), mediante a trajetória do protagonista. Partindo do princípio de que nesse conto se destacam as nuances do movimento irônico, apoiamo-nos nas idéias de Müecke (1995), de Frye (1973) e de Bakthin (1981) para investigar as estratégias e as técnicas empreendidas para a elaboração do discurso, bem como procuramos detectar as gradações que estruturam e moldam a conduta do protagonista.

O conto abre campo para que identifiquemos um universo mítico em que o protagonista é superior aos homens e ao próprio ambiente humano, já que é um ser divino ${ }^{1}$ - o Diabo. Parafraseando Petrarca, o Diabo não se arrepende e não se envergonha verdadeiramente de sua origem mítica. Ao contrário, tomaa como um empenho na tentativa de manipular a humanidade e tout aimable qu'il soit, il, tout court, recherche le pouvoir et la gloire, et il plaisante avec le respect et souligne une friponnerie éhonté.

O protagonista acredita que o poder de manipulação de Deus seja falacioso e extremamente impotente, daí crer que a força retórica do discurso lhe permitirá impor seus pontos de vista. O Diabo coloca-se como um autêntico

* Mestre em Letras, Unesp - São José do Rio Preto

1 "Se superior em condição tanto aos outros homens como ao meio desses homens, o herói é um ser divino, e a história sobre ele será um mito." (Frye, 1973, p. 39)

2 MOISÉS, M. Literatura: mundo e forma. São Paulo: Cultrix, 1982. p. 76. 
gênio que desbaratará quaisquer desideratos e empreendimentos encetados pelo Criador em relação à personalidade humana. Dessa forma, no diálogo entre ambos, adota a postura de sério e cínico, alegando que o inferno está dominado pela desorganização, sem regras, sem normas, sem cânones, sem ritual, fazendo com que o seu reino se encontre em condição de inferioridade perante a organização do reino divino. Apoiado nessa estratégia de pseudo-inferioridade e dominado pela idéia fixa de fundar a sua própria igreja entre os homens, declara a Deus que edificará um reino soberano na terra, por meio do qual se tornará o todo-poderoso do universo. Nesse sentido, enfatiza que as virtudes humanas são falazes e inconsistentes, constituindo uma fraude:

- Só agora concluí uma observação, começada desde alguns séculos, e é que as virtudes, filhas do céu, são em grande número comparáveis a rainhas, cujo manto de veludo rematasse em franjas de algodão. Ora, eu proponho-me a puxá-las por essa franja, e trazê-las todas para minha igreja; atrás delas virão as de seda pura... (Machado de Assis, 1983, p.113)

A metáfora (re)cria a realidade, uma vez que, além de lhe apontar a existência, acrescenta-lhe uma dimensão nova; a partir do signo de que se reveste, já é possível admitir que a realidade se manifesta como um dado essencial perante a interpretação do leitor. Por isso, a metáfora constitui o instrumento expressivo por excelência do texto literário. ${ }^{2}$ Nesse fragmento, a metáfora desenvolve uma conotação de epifania: ${ }^{3} \mathrm{o}$ Diabo passa a ter consciência de que, a personalidade humana possui uma natureza ambígua, daí seu estado de êxtase perante o Criador. O Diabo lhe enfatiza que, devido a essa relatividade, ser-lheá, sob o escrutínio da razão, possível a fundação de sua igreja.

No enunciado "as virtudes, filhas do céu, são em grande número comparáveis a rainhas, cujo manto de veludo rematasse em franjas de algodão", destaca-se uma tensão dinâmica que provém do viés metafórico: ao lado das belas e puras virtudes, representadas pelo "manto de veludo", emergem, no tempo e no espaço, fortes e imaculados pecados, manifestados pelas "franjas de algodão";

3 "A epifania constitui uma revelação peculiar da realidade interior de uma experiência, acompanhada por êxtase, como numa experiência religiosa mística.” (Booth, 1980, p. 342) 
trata-se de uma realidade deslumbrada pelo protagonista, despertando-lhe a paixão por uma hipotética vitória sobre o Criador.

Essa imagem metafórica, interligada a um plano intertextual, é como se o Diabo, assim como Páris, tivesse descoberto o calcanhar de Aquiles, ou seja, a vulnerabilidade humana. Dessa forma, a criatura humana aparentaria virtudes divinas sob o "manto de veludo", mas, concomitantemente, ocultaria pontos vulneráveis, com uma personalidade propensa ao pecado.

Booth (1980) entende por retórica o conjunto de técnicas e meios empregados com a intenção de manipular, persuadir, comover o interlocutor, a fim de que participe de um sistema de valores. Por isso, no romance, no conto, são de fundamental importância as estratégias e as técnicas discursivas adotadas, visto que, na essência, ocorre um trabalho meticuloso com a palavra, que (re)cria a realidade, e, nesse trabalho, a matéria-prima é o discurso, fonte perene de polêmicas e intermináveis discussões, suscitando um contínuo (re)examinar da obra literária.

Partindo desse pressuposto, o Diabo apóia-se na retórica do discurso para desmitificar o poder de Deus:

- Olhai bem. Muitos corpos que ajoelham aos vossos pés, nos templos do mundo, trazem as anquinhas da sala e da rua, os rostos tingem-se do mesmo pó, os lenços cheiram os mesmos cheiros, as pupilas centelham de curiosidade e devoção entre o livro santo e o bigode do pecado. Vede o ardor - a indiferença ao menos, - com que esse cavalheiro põe em letras públicas os benefícios que liberalmente espalha, - ou sejam roupas ou botas, ou moedas, ou quaisquer dessas matérias necessárias à vida ... Mas não quero parecer que me detenho em coisas miúdas; não falo, por exemplo, da placidez com que este juiz de irmandade, nas procissões, carrega piedosamente ao peito vosso amor e uma comenda...Vou a negócios mais altos...(Machado de Assis, 1983, p. 113-114)

Assumindo a postura de um protagonista divertissement a sério, o Diabo, presunçoso e cínico, deseja "abrir os olhos" de Deus para um novo dogma: a ambigüidade do comportamento humano. Assim, sob a vertente da comicidade, o Senhor é supostamente míope e não observa que seus filhos, astutos e dissimulados, fazem-no de tolo, pois vivem propensos ora à virtude, ora ao pecado. 
Estamos diante de uma ironia observável. ${ }^{4} \mathrm{O}$ protagonista adota a estratégia de um Nume que "sabe que sabe". Acredita, dessa forma, que possui a onisciência sobre todas as coisas e que Deus já não a possui, sendo assim, seria inferior, um "mestre vencido". De maneira jocosa e cínica, o Diabo deseja comandar os homens sob o beneplácito e a benesse do Criador e mediante a estratégia retórica da ironia sugere que o homem é mais atraído e seduzido pelo pecado do que pela virtude.

Em seu processo discursivo, ele não é nada modesto, ao contrário, vaidoso e ardil enfatiza que o preço do céu é "alto" e que o preço para entrar na sua igreja será "barato". No contexto do seu diálogo com Deus, surge a paródia irônica. ${ }^{5}$

Kierkegaard (1991) observa que, quando Sócrates alegava que apenas sabia que nada sabia, sua intenção era, com freqüência, tornar patente a fragilidade das opiniões de seus interlocutores, a inconsistência de seus argumentos, a obscuridade de seus conceitos. Conseqüentemente, sua afirmação de ignorância era irônica. Já nesse conto de Machado, o protagonista adota a estratégia de quem, pretensamente, conhece a natureza humana, acreditando-se superior a Deus. Dessa maneira, se o discurso de Sócrates estava alicerçado na humildade sapiente, o Diabo emprega um discurso baseado na presunção sapiente, invertendo, no plano da enunciação, a máxima socrática.

Nessa vertente discursiva, surge a sátira: ${ }^{6}$ mediante um enfático discurso moralista, o Diabo ataca as virtudes da igreja de Deus, considerando-as frágeis e sobretudo corrompidas pela genialidade dele, o Diabo, e pela força de suas "virtudes". Tendo em vista o contexto discursivo do diálogo entre ambos, intensifica-se a imagem de um anti-herói messiânico que irá fundar uma igreja às avessas à igreja de Deus.

O protagonista procura desqualificar o mundo apocalíptico ${ }^{7}$ habitado por Deus e pelos anjos. Esse universo mítico, para ele, é um arquétipo de praze-

4 Para Müecke (1995) neste tipo de ironia, podem ocorrer coisas vistas ou apresentadas como irônicas, configurando ironias de eventos, de personagem, de situação ou de idéias.

5 "O termo grego paródia significa "contracanto". O termo sugere uma idéia de comparação, ou melhor, de contraste, bem como uma distância crítica entre o texto parodiante e o texto parodiado, uma distancia manifestada pela ironia." (Hutcheon, 1978, p. 468)

6 "A sátira requer pelo menos uma fantasia mínima, um padrão moral implícito, uma atitude combativa. Assim, duas coisas são essenciais em seu universo: uma é a graça ou humor baseado na fantasia ou mesmo um senso de grotesco ou absurdo, a outra destina-se ao ataque." (Frye, 1973, p. 220-235.

7 "O mundo apocalíptico é um símbolo metafórico que representa o céu da religião, com suas bem-aventuranças e prazeres. Dessa forma, apresenta em primeiro lugar as categorias da realidade com as formas do desejo humano, e por isso torna-se uma aspiração da civilização humana." (Frye, 1973, p. 142) 
res, fomentando um paraíso que não se comparará com o triunfo e a glória de sua igreja demoníaca. E essa igreja destruirá o paraíso celeste, pois este ficaria deserto diante da política do preço "barato" adotada pela sua doutrina.

Assim, se no princípio foi o Verbo e existiu Cristo, como uma imagem demiurga e mítica, cuja palavra dotava-o de um poder carismático, sedutor, conferindo-lhe a aura de transmissor da Verdade, tornada acessível ao povo; agora, sê-lo-a suplantada pela inteligência do Diabo, por meio de um discurso que iria persuadir o homem, levando-o a aderir à nova igreja.

Esse discurso do protagonista é irônico, pois deseja o aplauso do Criador - o triunfo e a glória só teriam valor com o reconhecimento do vencido. Ao imaginar que conseguiria persuadir a Deus, o Diabo adota um procedimento sarcástico, já que a onipotência pertenceria a um novo soberano. Teríamos, então, uma função corretiva da ironia satírica que visa registrar desdém e zombaria, funcionando como uma catarse para a própria arte retórica, tomando Deus como um inexpressivo soberano que não teria mais um discurso convincente para persuadir o homem a aderir à doutrina e à política que o conduziriam ao mundo apocalíptico.

Ao se posicionar contra o Criador, o protagonista assume a postura de um anti-herói. ${ }^{8}$ Os heróis são indivíduos que, na independência dos seus sentimentos e vontade individuais, aceitam toda a responsabilidade dos atos que praticam e que, por virtude do imperativo da sua vontade particular, realizam o que é justo, nobre e moral. Opondo-se à ordem existente, o Diabo deseja, sob a máscara da astúcia e da inteligência, criar um mundo às avessas, no qual se tornaria o soberano de uma nova ordem.

Em sua mundividência sobre os seres e as coisas, Deus emprega um discurso irônico e satírico para refutar o discurso do oponente. Surge a ironia verbal, ${ }^{9}$ em que o Criador é uma personagem que sugere que os argumentos utilizados pelo adversário são frágeis e inconsistentes. É um discurso que não revelaria progressão semântica, preso a clichês e lugares-comuns, semelhante ao dos moralistas do mundo, pois fica implícito que Deus sempre soube que o homem "acende uma vela para Ele e outra para o Diabo".

8 HEGEL, G. W. F. Estética: a idéia e o ideal. Tradução: Orlando Vitorino et al. São Paulo: Nova Cultural, 1988. p. 155-158.

9 MÜECKE, D. C. A ironia e o irônico. Tradução: Geraldo Greson de Souza. São Paulo: Perspectiva, 1995. p. 35-40. 
- Tu és vulgar, que é o pior que pode acontecer a um espírito da tua espécie, replicou-lhe o Senhor. Tudo o que dizes ou digas está dito e redito pelos moralistas do mundo. É assunto gasto; e se não tens força, nem originalidade para renovar um assunto gasto, melhor é que te cales e te retires. Olha; todas as minhas legiões mostram no rosto os sinais do tédio que lhes dá. (Machado de Assis, 1983, p. 114)

O Diabo apóia-se num discurso cuja argumentação está fundamentada na citação de exemplos de pessoas que apresentam um comportamento ambíguo, divididas entre a virtude e o pecado. Essa retórica, sob a ótica do Criador, é inócua e estéril, pois está presa a formas estereotipadas ou clichês, que acabam por trivializar e desqualificar o valor do próprio ato discursivo. O ponto de vista, as idéias e as referências suscitados por meio desse tipo de argumentação não continham nenhuma informação nova que Deus não soubesse. Isso faz com que o Criador satirize o discurso do adversário, enfatizando que conhece esse discurso desde os primórdios da criação humana. Ora, nos exemplos destacados pelo Diabo, emergem clichês, sugerindo um enunciado moralista: o homem "viveria entre a virtude e o pecado", "entre Deus e o Diabo", bem como sobressaem lugares-comuns: o homem "busca o paraíso e as glórias da terra", e "é bom ou mau de acordo com o seu interesse".

A ironia satírica nesse contexto discursivo manifestado pelo Criador funciona como um ataque mordaz à retórica do protagonista. Nesse sentido, Deus nega a sapiência do Diabo e ao mesmo tempo indica que a estratégia retórica adotada não possui força semântica e discursiva, de tal forma que não persuade, não convence, não comove. É uma retórica com “franjas ornamentais", ou seja, não merece credibilidade. Assim, Deus sugere que o oponente é apenas pretensioso e está auto-iludido. O Criador deixa implícito que a retórica do protagonista é um pseudocanto de sereia, funcionando como enganosas rede, teia, imã, que não atraem, nem prendem e nem aderem, um condão mágico-trágico que abre as portas de realidades tão-somente para quem nele se engolfa e se perde, daí ser um embuste, uma emboscada, que, tragicamente, despertam o fascínio para glórias e triunfos volitivos e efêmeros.

O Diabo, no diálogo com Deus, quer vencê-lo pela ironia e pela sátira, e Deus, por sua vez, emprega o mesmo processo para despertá-lo de sua paixão pelo poder, citando o exemplo de um ancião que acaba de ganhar o céu: 
- Depois de uma vida honesta, teve uma morte sublime. Colhido em um naufrágio, ia salvar-se numa tábua, mas viu um casal de noivos, na flor da vida, que se debatia já com a morte, deulhe a tábua de salvação e mergulhou na eternidade. Nenhum público: a água e o céu por cima. Onde achas aí a franja de algodão?

- Senhor, eu sou, como sabeis, o espírito que nega. - Negas esta morte?

- Nego tudo. A misantropia pode tomar aspecto de caridade; deixar a vida aos outros, para um misantropo, é realmente aborrecê-los...

- Retórico e sutil! Exclamou o Senhor. Vai, vai, funda a tua igreja; chama todas as virtudes, recolhe todas as franjas, convoca todos os homens... Mas vai! vai! (Machado de Assis, 1983, p. 114-115)

Nesse diálogo, destaca-se a presença da ironia satírica com a intenção de zombar, ridicularizar, embaraçar e humilhar o outro, facultando a presença da vítima irônica. ${ }^{10}$

Em um primeiro momento, Deus apóia-se na metáfora da "franja de veludo", que representa a pureza e a virtude, para que se contraponha à metáfora da "franja de algodão", que simboliza a fraqueza e o pecado. Simbolicamente, o ato de solidariedade humana perpetrado pelo ancião serve de estratégia retórica irônica para que o Criador ataque o ponto de vista defendido pelo adversário: a glória plena e o triunfo autêntico seriam conseguidos mediante a prática do bem ao próximo e esse seria um argumento supostamente sólido e consistente para refutar e para desqualificar a intenção do Diabo de fundar a sua igreja. Ora, o Criador procura demonstrar que as virtudes facultam o poder perene, assim como também não nega que muitos homens são tentados e seduzidos pelo pecado, conquistando um poder falacioso e efêmero.

Todavia, teimoso e rebelde, o Diabo nega as virtudes celestiais e, ao fazê-lo por ortodoxia demoníaca, sob o pretexto de que sua verdade é a verdade, desvaloriza o discurso divino e salienta que suas "virtudes" substituiriam as

10 "A ironia tem sempre uma aresta, às vezes um ferrão, ao contrário da sinédoque, a ironia sempre tem um "alvo", que alguns chamam de "vítima". Como as conotações desses dois termos se amalgamam, o fio da ironia é sempre cortante. Observa-se, então, que a ironia consegue funcionar e funciona taticamente a serviço de uma vasta gama de posições políticas, legitimando ou solapando uma grande variedade de interesses." (Hutcheon, 2000, p. 26-33) 
celestes. Essa postura de espírito obstinado faz renunciar à própria tarefa crítica, mediante a provável lógica dos argumentos do Criador. Essa renúncia do exercício reflexivo e analítico, em favor do egocentrismo absoluto, é um componente que depõe contra a falta de perspicácia, contra o espírito de imparcialidade, inviabilizando um conhecimento autêntico e pleno da personalidade humana.

Simbolicamente, o ancião ao ofertar a sua própria vida para salvar o casal de noivos, aplicando a doutrina do amor ao próximo, mergulha na água para adentrar no mundo apocalíptico da bem-aventurança. Dessa forma, ocorre uma espécie de ritual do batismo, como prêmio pelo ato praticado.

Chevalier (1993) revela que, na liturgia das diversas confissões cristãs, há duas fases do alcance simbólico: a imersão e a emersão, símbolos de purificação e renovação. A imersão indica o desaparecimento do ser pecador nas águas da morte, ocorrendo a purificação, com o retorno do ser às fontes da vida; já a emersão revela a aparição do ser em estado de graça, purificado, reconciliado com uma fonte divina de vida nova. Sob essa vertente, podemos observar que o ancião se purifica, "perde as franjas de algodão" ao obedecer à doutrina do Criador, sendo recolhido no Éden, mundo apocalíptico dos virtuosos.

Mesmo assim, o Diabo não se impressiona com esse discurso e refuta-o, empregando a ironia satírica e a galhofa. Contudo, o viés irônico é uma armadilha contra o próprio discurso do protagonista. Ao afirmar enfaticamente que o "seu espírito é o da negação", contesta e ridiculariza o exemplo do ancião fornecido por Deus como um exemplo que não merece crédito: o egoísmo pode simular o amor e dissimular suas "franjas de algodão". O Diabo afirma explicitamente em seu enunciado a realidade do pecado, estratégia que contradiz e descaracteriza seu próprio discurso, pois, quando lhe convém e lhe agrada, ele sabe "afirmar" em seu benefício.

Procurando demonstrar plena força e autêntica autoridade para defender o pecado, o protagonista sugere que o ancião é uma fraude, símbolo do fingimento, do mau que quis parecer bom. Nesse contexto, teria conseguido enganar a Deus, que identificou virtude onde havia apenas pecado. Sob esse aspecto, o protagonista põe em dúvida a própria sapiência do Criador, que estaria velho e ultrapassado.

$\mathrm{O}$ cômico intensifica-se à medida que funciona como uma defesa do pecado e como uma desvalorização da sabedoria divina, mesmo diante de uma situação real de virtude. $\mathrm{O}$ ato praticado pelo ancião e a sua refutação pelo protagonista é uma estratégia calculada para desmitificar as virtudes do amor, 
da caridade e da bondade, que, ideologicamente, seriam uma fraude, valorizadas por um pseudo-sábio.

Não suportando o cinismo e a presunção do Diabo, Deus permite que ele funde a sua igreja, ou seja, ironiza, no próprio ato discursivo, o laissez-faire.

- Sim, sou o Diabo, repetiu ele; não o Diabo das noites sulfúreas, dos contos soníferos, terror das crianças, mas o Diabo verdadeiro e único, o próprio gênio da natureza, e que se deu aquele nome para arredá-lo do coração dos homens. Vede-me gentil e airoso. Sou o vosso verdadeiro pai. Vamos lá: tomai daquele nome, inventado para meu desdouro, fazei dele um troféu e um lábaro, e eu vos darei tudo, tudo, tudo, tudo, tudo, tudo... (Machado de Assis, 1983, p.115)

Nesse discurso, o Diabo, no plano intertextual, apóia-se no texto bíblico para persuadir, convencer e comover o homem, procurando levá-lo a aderir aos seus pontos de vista. Dessa forma, esse discurso promove a intertextualidade ${ }^{11} \mathrm{e}$ constitui uma estratégia calculada de manipulação.

No texto bíblico, o Diabo procura manipular Jesus, propondo-lhe um acordo, em que o Messias seria recompensado, isto é, receberia um objeto de valor positivo - os reinos do mundo e a glória deles, sendo que ele, Diabo, não era dono desses reinos, o que se representa, portanto, uma retórica permeada pela simulação e pela dissimulação; por outro lado, Jesus deveria adorá-lo: "O Diabo o transportou a um pináculo, e mostrou-lhe todos os reinos do mundo, e a glória deles. E disse-lhe: Tudo, tudo isto te darei se, prostrado, me adorares. (Novo Testamento, 1979, p. 3)

Nesse conto de Machado, o Diabo promete glórias, triunfos, poderes, riquezas, sabedoria àqueles que seguirem sua doutrina. $\mathrm{O}$ emprego enfático do pronome indefinido "tudo" funciona como uma espécie de política demagógica, constituindo um "grande negócio" para a ascensão da nova igreja: é uma estratégia para cortejar as massas, prometendo a instauração de realidades sedutoras, com vantagens e lucros terrestres. Desse modo, finge, como se tivesse a onipotência para "tudo" ofertar ao homem, desde que este o adorasse e lhe

11 "No espaço do texto, vários enunciados, apoiados em outros textos, podem se cruzar e se neutralizar, propiciando com que se instale a noção de intertextualidade, engendrando uma estratégia dialógica." (Kristeva, [s.d.], p. 43) 
fosse subserviente. Ao adotar essa estratégia retórica, ele deseja tornar-se o soberano absoluto do universo, já que não admite dividir o poder com Deus, por isso busca alterar o modus vivendi da criatura humana, afetando o status quo, e, ipso facto, facultar uma nova ordem, em que a multidão lhe outorgue plenos poderes para reinar. ${ }^{12}$

O Diabo procura instalar um "mundo às avessas", ou seja, um mundo com a inversão de valores, em que pecados condenados por Deus passem a constituir "virtudes" perenes, naturais e legítimas. Nesse novo reino demoníaco, ocorre a inversão de antigos valores morais, de antigas normas e regras, que passam a ser considerados obsoletos e desprezíveis. Na ordem desse novo mundo, a sociedade passa a estar unida por uma espécie de doutrina rígida, em que pecados são transformados em arquétipos de bem-aventurança, como a grande valorização que se outorga aos pecados capitais: soberba, luxúria, preguiça, avareza, ira, gula e inveja.

Ao transformá-los em "virtudes", o protagonista desmitifica a retórica do texto bíblico que os condena, bem como parodia o Purgatório de Dante, que apresenta inúmeros espíritos sofrendo, em lancinante angústia por causa desses sete pecados. Já na Igreja do Diabo, as pessoas são felizes e recompensadas ao praticarem essas novas "virtudes".

Como um político eloqüente, o Diabo utiliza-se de um discurso que se apóia em autores da literatura e da história para convencer o homem, indicando o "poder" dos pecados:

Nada mais curioso, por exemplo, do que a definição que ele dava da fraude. Chamava-lhe o braço esquerdo do homem; o braço direito era a força; e concluía: muitos homens são canhotos, eis tudo. Ora, ele não exigia que todos fossem canhotos; não era exclusivista. Que uns fossem canhotos, outros destros; aceitava a todos, menos os que não fossem nada. A demonstração, porém, mais rigorosa e profunda, foi da venalidade. [...] como é que não podes vender a tua opinião, o teu voto, a tua palavra, a tua fé, coisas que são mais do que tuas, porque são a própria consciência, isto é, tu mesmo? (Machado de Assis, 1983, p. 117)

12 "O político busca governar não só motivado pelo salário ou posição, mas sobretudo pelo poder, e isso faz com que se apaixone pelo poder e procure a todo custo conservar privilégios, favores e glórias que o cargo lhe oferta. Nesse sentido, o seu partido deseja o monopólio do poder". (Weber, 1980, p. 32-33) 
Bakthin (1991) destaca que as diversas violações da marcha universalmente aceita, bem como dos acontecimentos, das normas e regras comportamentais estabelecidas e da etiqueta, incluindo-se também as violações do discurso, perfazem um enfoque mordaz à atualidade ideológica e constituem alguns dos atributos da sátira menipéia. ${ }^{13}$

Ao inverter a ordem dos valores morais defendidos pela igreja de Deus, o Diabo, adotando estratégias da sátira menipéia, procura aniquilar a antiga cosmovisão de valores, normas e regras. Ao valorizar todos os tipos de "pecados", transformando-os em "virtudes" na sua doutrina, promete vantagens terrestres e lucros pecuniários ao homem. Ao glorificar os pecados capitais, procura ridicularizar o discurso bíblico, bem como busca descaracterizar e dessacralizar o discurso das almas sofredoras, no Purgatório de Dante. Destaca-se, dessa maneira, a intertextualidade das diferenças. ${ }^{14}$

Nesse novo reino, com a inversão da ordem habitual de valores, instaura-se, em certo sentido, uma vida carnavalesca,${ }^{15}$ uma vida às avessas.

Assim, as leis, proibições e restrições, que determinavam o sistema e a ordem da vida comum antes da fundação da igreja do Diabo, revogam-se; é permitido violar a antiga doutrina e a vida ganha uma espécie de tom carnavalesco: todas as venalidades são valorizadas, a fraude é vangloriada. A hipocrisia e a arte de dissimulação são extremamente valorizadas, a traição é uma grande "virtude". A corrupção torna-se nobre e gloriosa, a calúnia mediante retribuição pessoal passa a ser um grande triunfo. E, sobretudo, no relacionamento entre os homens, tornam-se regra áurea e lei máxima a indiferença, o ódio e o desprezo.

Revelando uma típica atitude schoupeaueriana, de que os fracos não conseguem sobreviver e vencer, o Diabo valoriza a força, a astúcia e a arte de enganar. Nesse sentido, como declarou Roterdã [s.d.], o homem passa a viver uma espécie de constante comédia, empregando mil disfarces para aparecer em cena e desempenhar os seus papéis habilmente, até que o diretor, após havê-lo feito usar inúmeros disfarces, da miséria à glória, o obriga a deixar o palco, depois de inúmeras representações.

$\mathrm{Na}$ condição de pretenso soberano onisciente, onipotente, onipresente, procurando desmitificar a própria autoridade de Deus, o Diabo crê-se triunfador e rei da terra: “A previsão do Diabo verificou-se. Todas as virtudes cuja capa de

13 BAKTHIN, M. Problemas da poética de Dostoiévski. Tradução: Paulo Bezerra. Rio de Janeiro: Forense Universitária, 1981. p. 97-104.

14 "Falar de paródia é falar de intertextualidade das diferenças, do lado da ideologia dominante surge a contra-ideologia, a descontinuidade, com um efeito de deslocamento, de contradição". (Sant'anna, 1991, p. 28-29)

15 BAKTHIN, op. cit., p. 105-118. 
veludo acabava em franja de algodão, uma vez puxadas pela franja, deitavam a capa às urtigas e vinham alistar-se na igreja nova." (Machado de Assis, 1983, p. 119)

Ao valorizar a profanação, a excentricidade, a fraude, o Diabo deseja ridicularizar a doutrina divina, porém, o homem só pode desfrutar de uma carnavalização com liberdade restrita e limitada, pois é proibido quaisquer manifestações de apreço pelas antigas virtudes.

Acreditando que é detentor de um discurso persuasivo e convincente, o Diabo aplaude a si mesmo, beneficiando-se com a adesão das multidões: "O Diabo incutia-lhes, a grandes golpes de eloqüência, toda nova ordem de coisas, trocando a noção delas, fazendo amar as perversas e detestar as sãs."(Machado de Assis, 1983, p. 117)

Para coroar a sua vitória com a obediência humana, o protagonista desejou eliminar a solidariedade humana e, por meio de um discurso cínico, vê-se a si mesmo como sapiente e cita, ironicamente, o discurso de um padre de Nápoles para confirmar a veracidade do seu próprio discurso: "Leve a breca o próximo! Não há próximo!”. Entretanto, esse discurso está dominado pelo viés irônico, pela galhofa. É o discurso de um fingidor. Ao citar o discurso alheio, o Diabo afeta a credibilidade do seu próprio discurso, pois cai em contradição ele parafraseia o discurso do próximo. Dessa forma, inconscientemente, ele efetua um ato falho - afirma, na enunciação, a importância do próximo.

Por outro lado, ele emprega uma postura cínica e hipócrita e, ao mesmo tempo, conservadora e machista, ao enfatizar que o único próximo que ele aceitaria que se amasse seriam as mulheres, que surgem como objetos do prazer. A mulher, numa imagem simbólica, emerge como Afrodite, mito do prazer, que precisa de um deus - o homem -, e este seria o "mundo" da mulher, enquanto o homem, por meio de uma metáfora irônica, poderia ter vários "mundos", ou seja, inúmeras amantes para desfrutar o prazer de amar a si mesmo. Nessa ótica, o intelecto teria sexo e seria masculino, constituindo o amor uma filáucia narcisista.

Assim, esse discurso do Diabo retoma a referência de Fromm (1974) sobre a pessoa egoísta e narcisista. Para Fromm (1974), a pior dor e o maior castigo é a rejeição. O homem não a suporta quando é manifestada por uma mulher, por isso deseja a todo custo tirar vantagens desse objeto amado, tornando-se, como enfatizou Freud, egocêntrico, ansioso por prazer, e com isso aspira a retirar o amor da mulher para tê-lo em sua própria pessoa, para que possa identificar a si mesmo como um homem pseudovaloroso e pseudoconquistador.

Preso a uma visão limitadora, restrita e parcial do ser humano, o Diabo, inebriado e apaixonado pelo poder, passa a crer na fidelidade humana. Entre- 
tanto, os súditos, no decorrer do tempo, passaram a sentir atração pelas antigas virtudes divinas, traindo-o. Dessa maneira, o protagonista, que se julgava astuto e sábio, é enganado pelo homem que, dissimuladamente, cultivava as virtudes que conduziam ao céu:

Um dos seus melhores apóstolos era calabrês, varão de cinqüenta anos, insigne falsificador de documentos, que possuía uma bela casa na campanha romana, telas, estátuas, biblioteca, etc. Era a fraude em pessoa; chegava a meter-se na cama para não confessar que estava são. Pois esse homem, não só furtava ao jogo, como ainda dava gratificações aos criados. Tendo angariado a amizade de um cônego, ia todas as semanas confessar-se com ele, numa capela solitária; e, conquanto não lhe desvendasse nenhuma de suas ações secretas, benzia-se duas vezes, ao ajoelhar-se, e ao levantar-se. O Diabo mal pôde crer tamanha aleivosia. (Machado de Assis, 1983, p. 120)

A grande ironia do conto decorre do fato de que, antes de fundar a sua igreja, o Diabo contestava a fragilidade das virtudes dos súditos de Deus, propensos à perfídia, atraídos pelo pecado, mas, ao ver concretizada a fundação de sua igreja, o protagonista é traído pela sua própria pretensão de invulnerabilidade e pela crença de fidelidade dos seus seguidores, conseqüentemente, julgou-se soberano infalível e indestrutível - o que intensificou sua paixão e sua cegueira pelo poder. Ignorando que as artes da simulação e da dissimulação são empregadas como estratégias para atender aos interesses particulares do ser humano, o Diabo demonstrou-se vulnerável e pseudo-sábio. Essa observação é manifestada por Deus quando o adversário o procura em busca de uma explicação. Deus ironiza e satiriza a ingenuidade do oponente: "Que queres tu, meu pobre Diabo? As capas de algodão têm agora franjas de seda, como as de veludo tiveram franjas de algodão. Que queres tu? É a eterna contradição humana." (Machado de Assis, 1983, p. 120)

Esse discurso de Deus lembra o discurso de Hamlet: "Ser ou não ser... Eis a questão. O que é mais nobre para a alma: suportar os dardos e arremessos do fado sempre adverso, ou armar-se contra um mar de desventuras e dar-lhes fim tentando resistir-lhes? (Shakespeare, [s.d.], p. 80). Ora, Hamlet foi atormentado pela contradição, assim como o Diabo também estava sendo. Integrado na realidade do "eu" emotivo, semelhante a Narciso, que projetou a sua 
própria imagem no espelho, o Diabo coroa a si mesmo como um novo Deus. Ao acreditar que seria o eterno soberano perante o homem, ignorou que a astúcia, a inteligência e a arte do engano poderiam ser empregadas contra ele mesmo, assim como já o vira em relação a Deus.

Nesse último diálogo entre Deus e o Diabo, o Criador emprega a paródia irônica para ridicularizar a arte discursiva do Diabo: "As capas de algodão têm agora franjas de seda, como as de veludo tiveram franjas de algodão. Que queres tu? É a eterna contradição humana". Deus satiriza a pseudo-sapiência do Diabo, produzindo um discurso que manifesta a comicidade da paródia. Bergson (1980) destaca que esse tipo de comicidade surge "quando nos apresentam uma coisa, antes respeitada, como medíocre e vil, em estado de degradação"(Bergson, 1980, p. 66-67). Essa degradação suscita uma transposição de algo sério em bufão. Esse desvio, nesse conto, atinge o espírito do protagonista, que se apegou à crença de fidelidade absoluta e irrestrita do ser humano à sua doutrina, logo, o Diabo apaixonou-se por si mesmo, preferindo ignorar o "espírito de negação". O enunciado "meu pobre Diabo" desperta o riso. A doutrina do Diabo suscita infiéis, além disso, o adjetivo "pobre", nesse contexto, humilha, degrada e indica uma contundente derrota, bem como consolida a superioridade de Deus, que já sabia o que iria acontecer com a igreja do Diabo, ao passo que este se encantou, deslumbrou-se, apaixonou-se pela própria imagem de superioridade.

Utilizando-se da ironia e da sátira, mediante a trajetória do protagonista, indica que as estratégias da simulação e da dissimulação são inerentes e intrínsecas da natureza humana, dividida entre a virtude e pecado. Desse modo, a personalidade humana é fiel a si mesma, ou seja, a fidelidade é uma fraude e um mito. O Diabo, um ser mítico, que se julgava todo-poderoso e invencível, foi enganado pela astúcia e inteligência do homem, que se adapta às circunstâncias e às situações, com a intenção de obter vantagens e lucros tanto na terra como no céu. Nesse sentido, na arte do engano, a personalidade humana é muito mais astuta e inteligente que o Diabo e a estratégia do fingimento está presente no discurso, na conduta, no comportamento da criatura humana.

Presunçoso, vaidoso e preso a uma pseudo-sapiência, o Diabo adotou uma política demagógica de "tudo" dar ao homem, mas, "pobre Diabo", só tinha o pecado e o ser humano não se contenta só com o pecado, ele quer também a virtude, ou seja, aspira à "franja de veludo" e à "franja de algodão". 


\section{RESUMO}

O Diabo funda a sua igreja na terra, no entanto, presunçoso e desatento, o protagonista é enganado pela natureza ambígua do homem. Assim, o discurso e o movimento irônico indicam que a fidelidade é uma fraude.

Palavras-chave: Machado de Assis, “A igreja do Diabo”, ironia, fraude.

\section{RÉSUMÉ}

Le diable fonde son église sur la terre, pourtant, présomptueux et distrait, il est trompé par la nature ambigüe de l'homme. Ainsi, le discours et le mouvement ironique montrent que la fidélité est une fraude.

Mots-clé: Machado de Assis, “A igreja do Diabo”, ironie, fraude.

\section{REFERÊNCIAS}

ALIGHIERI, D. O Purgatório. In: . A Divina comédia. Tradução: Hernâni Donato. São Paulo: Abril Cultural, 1981. p. 127-232.

BAKTHIN, M. Problemas da poética de Dostoiévski. Tradução: Paulo Bezerra. Rio de Janeiro: Forense Universitária, 1981.

BERGSON, H. O riso: ensaios sobre a significação do cômico. Tradução: Nathanael C. Caixar. Rio de Janeiro: Zahar, 1980.

BÍBLIA, N. T. Português. Biblía Sagrada. Tradução: João Ferreira de Almeida. São Paulo: Sociedade Bíblica Trinitarina do Brasil, 1979.

BOOTH, W. A retórica da ficção. Tradução: Maria Teresa H. Guerreiro. Lisboa: Arcádia, 1980. 
DEZAN, E. Sob o signo da fraude: uma personagem auto-iludida

CHEVALIER, J.; GHEERBRANT, A. Dicionário de símbolos. Tradução: Vera da Costa e Silva et al. Rio de Janeiro: J. Olímpio, 1993.

FIORIN, J. L. Elementos de análise do discurso. São Paulo: Contexto, 1989. . As astúcias da enunciação. São Paulo: Ática, 1996.

FROMM, E. Análise do homem. Tradução: Octavio Alves Velho. Rio de Janeiro: Zahar, 1974.

FRYE, N. Anatomia da crítica. Tradução: Péricles Eugênio da Silva. São Paulo: Cultrix, 1973.

HEGEL, G. W. F. Estética: a idéia e o ideal. Tradução: Orlando Vitorino et al. São Paulo: Nova Cultural, 1988.

HUTCHEON, L. Ironie et parodie: Stratégie et structure. Poétique, Paris, n. 36, p. 467477, nov. 1978.

Ironie, satire, parodie: une approche pragmatique de l'ironie. Poétique, Paris, n. 46, p. 440-455, avr. 1981.

Teoria e política da ironia. Tradução: Júlio Jeha. Belo Horizonte: UFMG, 2000.

KERBRAT-ORECCHIONI, C. L'énonciation de la subjectivité dans le langage. Paris: Armand Colin, 1980.

KIERKEGAARD, S. O conceito de ironia. Tradução: Álvaro L. M. Valls. Petrópolis: Vozes, 1991.

KRISTEVA, J. Semiótica do romance. Tradução: Fernando Cabral Martins. Lisboa: Arcádia, [19-].

LAUSBERG, H. Elementos de retórica. Tradução: R. M. Rosado Fernandes. Lisboa: Fundação Calouste Gulbenkian, 1967.

MACHADO DE ASSIS, J. M. A igreja do Diabo. In: Contos. São Paulo: Moderna, 1983. p. 111-120.

MOISÉS, M. Literatura: mundo e forma. São Paulo: Cultrix, 1982.

MÜECKE, D. A ironia e o irônico. Tradução: Geraldo Gerson de Souza. São Paulo: Perspectiva, 1995.

ROTERDÃ, E. Elogio da loucura. Tradução: Júlio Abreu de Matos Guerra. São Paulo: Novo Horizonte, [19-]. 
SANT'ANNA, A. R. Paródia, paráfrase e Cia. São Paulo: Ática, 1991.

SHAKESPEARE, W. Hamlet. Tradução: Carlos Alberto Nunes. São Paulo: Melhoramentos, [19-].

WEBER. M. Os pensadores. Tradução: Maurício Tragtenberg. São Paulo: Abril Cultural, 1980. 
